\title{
Transtorno mental: dificuldades enfrentadas pela família
}

MENTAL DISORDERS: DIFFICULTIES FACED BY THE FAMILY

TRASTORNO MENTAL: DIFICULTADES ENFRENTADAS POR LAFAMILIA

\section{Maria Alice Ornellas Pereira ${ }^{1}$, Alfredo Pereira $\mathrm{Jr}^{2}$}

$$
\begin{aligned}
& 1 \text { Professora Assistente } \\
& \text { Doutora do } \\
& \text { Departamento de } \\
& \text { Enfermagem } \\
& \text { Psiquiátrica e Ciências } \\
& \text { Humanas da Escola de } \\
& \text { Enfermagem de } \\
& \text { Ribeirão Preto da USP } \\
& \text { (EERP-USP). } \\
& \text { ornelas@eerp.usp.br } \\
& 2 \text { Professor Adjunto do } \\
& \text { Departamento de } \\
& \text { Educação do Instituto } \\
& \text { de Biociências da } \\
& \text { Universidade Estadual } \\
& \text { Paulista (UNESP), } \\
& \text { Campus de Botucatu. } \\
& \text { apj@ibb.unesp.br }
\end{aligned}
$$

\author{
RESUMO \\ Utilizando uma metodologia \\ qualitativa (entrevistas \\ abertas, desenho-estória e \\ análise temática) \\ identificamos e analisamos 4 \\ categorias (descompasso \\ temporal, culpa, conflitos $e$ \\ perdas) presentes no discurso \\ de mães (e uma irmã) de \\ pacientes psiquiátricos do \\ Núcleo de Atenção \\ Psicossocial (NAPS) de \\ Ribeirão Preto/SP, e \\ avaliamos sua importância \\ conforme o objetivo de se \\ entender a dinâmica da \\ relação entre serviço de saúde \\ mental, paciente psiquiátrico e \\ sua familia.
}

\section{PALAVRAS-CHAVE}

Transtornos mentais. Família.

Interação Social.

Enfermagem psiquiátrica.

\section{ABSTRACT}

Using a qualitative methodology (open interviews, story-drawing and thematic analysis), we identify and analyze 4 categories (temporal mismatching, guilt, conflict and loss) found in the discourse of mothers (and one sister) of psychiatric patients receiving treatment at the Center for Psycho-Social Care (NAPS) in Ribeirão Preto, SP, Brazil, and also evaluate the importance of such categories with a view to understanding the dynamical relationships among mental health services, patients and their families.

\section{KEYWORDS}

Mental disorders.

Family.

Interpersonal relations.

Psychiatric nursing.

\section{RESUMEN}

Usando una metodología cualitativa (entrevistas abiertas, diseño-historia y análisis temático) en este trabajo identificamos y analizamos 4 categorías (descompás temporal, culpa, conflictos y pérdidas) presentes en el discurso de madres (y una hermana) de pacientes psiquiátricos del Núcleo de Atención Psicosocial (NAPS) de Ribeirão Preto/SP, y evaluamos su importancia de acuerdo con el objetivo de entender la dinámica de la relación entre servicio de salud mental, paciente psiquiátrico y su familia.

\section{PALABRAS CLAVE}

Transtornos mentales. Familia.

Relaciones interpersonales. Enfermeria psiquiatria. 


\section{INTRODUÇÃO}

O atual modelo de assistência em saúde mental em regime aberto preconiza um ganho terapêutico que atenda às necessidades de relacionamento afetivo e social do paciente. Deste modo, os Núcleos de Atenção Psicossocial (NAPS) têm desenvolvido formas de assistência voltadas para tais necessidades, que incluem a atenção a grupos de familiares dos pacientes, coordenados por membros da equipe multidisciplinar atuante no NAPS. No contexto desta proposta, participamos de reuniões de grupos de familiares de pacientes no NAPS-Ribeirão Preto, onde realizamos uma pesquisa tendo como objetivo identificar as dificuldades sentidas em seu convívio com o doente mental. Apresentamos aqui um sumário das entrevistas realizadas, acompanhado de uma análise do conteúdo que se expressa nas mesmas. Esta análise está centrada nas categorias temáticas que pudemos identificar como sendo as mais relevantes para entender a dinâmica da relação entre serviço de saúde-paciente-família.

\section{REVISÃO HISTÓRICO- BIBLIOGRÁFICA}

Para abordar de modo satisfatório a questão dos encargos da família do portador de transtorno mental é necessário que se adote uma perspectiva histórica. A história da assistência em psiquiatria mostra que a atenção reservada à família é relativamente recente. Enquanto apenas os manicômios respondiam pelas necessidades de cuidados prestados nesta área, a interação entre instituição, paciente, família e comunidade se encontrava incipiente. O problema era colocado sempre "fora", em um espaço longínquo, alheio ou estranho, o que pode ser interpretado como indício do real afastamento frente à consideração do processo saúde/doença, havendo olhares voltados apenas à doença, não contemplando a pessoa com sua história e seu contexto.A partir da década de quarenta e cinqüenta do século passado, acentuandose mais na década de sessenta, pesquisas de estudiosos na Europa e Estados Unidos voltaram olhares para a família e efetuaram estudos que buscavam compreender como as relações familiares estariam diretamente ligadas ao surgimento dos transtornos mentais. $\mathrm{O}$ término da segunda guerra mundial trouxe inúmeras transformações na sociedade e es- tas se refletiram também na assistência psiquiátrica, havendo grande interesse pelos aspectos sociais e familiares. Com os movimentos mundialmente conhecidos de análise e crítica anti-institucional em países ocidentais, surgiram modelos de intervenção que visavam reduzir ou eliminar a utilização dos hospitais psiquiátricos trazendo, entre outras conseqüências, a família para o cenário da assistência.

No Brasil, a partir da década de 1970, surgiu o movimento de Reforma Psiquiátrica, que busca substituir os manicômios por iniciativas sociais, culturais, políticas, científicas, jurídicas, assim como modificar os conceitos e a relação da sociedade com as pessoas portadoras de transtornos mentais. A Política de Saúde Mental no Brasil foi fortemente influenciada pela experiência italiana que teve à frente Franco Basaglia. No entanto, na prática, não encontramos uma aplicação efetiva das diretrizes desse modelo. As propostas expressam em seus objetivos uma preocupação em reduzir o número de pacientes internados e o tempo de internações dos mesmos, além de conter referência à participação das famílias e das comunidades na assistência em Saúde Mental, porém os papéis que competem a cada um destes parceiros não são ainda bem definidos ou mesmo compreendidos ${ }^{(1)}$.

Nos modelos anglo-saxões, as intervenções relacionadas à família são desenvolvidas tendo como finalidade a questão econômica, visando a diminuição das taxas de internação ${ }^{(2)}$. Segundo os autores citados, essas experiências não têm a preocupação de assumir uma perspectiva global, que proponha a estruturar o serviço territorial e formar uma triangulação entre paciente-família e serviço de saúde. Neste contexto, gradativamente emergem novas estratégias, favorecendo um nível mais coletivo de participação, reconhecendo o valor da família na atenção à saúde mental e inserindo-a no projeto terapêutico, em busca de uma melhor qualidade de vida tanto para quem é cuidado quanto para quem cuida. A análise das necessidades complexas de um paciente nos leva a colocá-lo em áreas específicas (assistenciais, relações humanas, familiares, trabalho etc.). Então, interagir com o sofrimento significará interagir também com estas áreas de problemas ${ }^{(3)}$. Assim, vemos que existe um consenso que a família consiste a primeira rede social da pessoa; é fundamental, quer para a
Transtorno mental: dificuldades enfrentadas pela família 
Maria Alice O. Pereira Alfredo Pereira Jr.

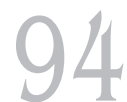

Rev Esc Enferm USP 2003; 37(4): 92-100. manutenção do doente mental fora do hospital psiquiátrico, ou em uma visão mais ampla de assistência à saúde mental, que considera essenciais os recursos e a atuação da comunidade.

Isso contribui para o entendimento da família como a unidade básica da saúde, num modelo de intervenção que possibilite resolver os problemas cotidianos, diminuindo o stress e, indiretamente, as recaídas ${ }^{(4)}$. $\mathrm{Na}$ visão da família como a unidade básica podemos pensar que para cumprir o papel de provedora ela necessita, além dos recursos institucionais, do preparo e do apoio de profissionais.

Estudando os problemas enfrentados pela convivência da família com o doente mental, foram encontrados três tipos de sobrecarga impostas às famílias: financeira, física e emocional, identificando ainda alterações nas atividades de lazer e sociabilidade ${ }^{(5)}$. Foram identificados e classificados os encargos familiares em objetivos e subjetivos ${ }^{(6)}$. Os encargos objetivos incluem: tempo utilizado para a assistência, redução das relações sociais e do tempo livre, dificuldade econômica, dificuldade quanto ao trabalho. Quanto aos encargos subjetivos: o desenvolvimento de sintomas de ansiedade, efeitos psicossomáticos, sentimentos de culpa, de vergonha, de desorientação quanto às informações sobre os distúrbios mentais e isolamento social.

Pesquisando famílias por meio de visitas domiciliares $^{(7)}$ foram identificadas, entre outras, as dificuldades surgidas no enfrentamento dos problemas sociais e econômicos, a desconfiança depositada na pessoa que convive com o transtorno, o estigma, o desprezo e o desrespeito dos que o cercam. Outro estudo teve como foco familiares que cuidavam de uma pessoa portadora de doença mental ${ }^{(8)}$. Nestes dois temas centrais foram encontrados o caráter relacional e temporal da convivência com o doente mental. Depois do estágio inicial do choque, os familiares passaram a aceitar a nova situação de relacionamento com a pessoa. Esta aceitação foi entendida como um processo que ocorre ao longo do tempo, requerendo uma série de mudanças na vida familiar. Por outro lado, os investimentos em trabalhos que visam dar esse suporte ainda são escassos, deixando um campo de atuação carente e sem muitas respostas. Pesquisando o drama das famílias diante da internação psiquiátrica ${ }^{(9)}$, consta- tou-se que os profissionais de saúde possuem uma visão idealizada da família. Primeiro, concebendo-a como um grupo nuclear imerso numa ampla relação de parentesco que, por sua própria natureza, seria um recurso terapêutico para o doente mental. Segundo, acreditando que a família tem a obrigação de ficar com o doente. Estas considerações reforçam a importância do trabalho interdisciplinar na busca de caminhos que promovam a melhoria na qualidade de vida dos núcleos familiares, criando possibilidades reais de vínculos que poderão conduzir às transformações da rede de assistência.

\section{MATERIAIS E MÉTODO}

Esta pesquisa foi realizada durante o primeiro semestre de 2001, junto ao NAPSRibeirão Preto (Núcleo de Atenção Psicossocial de Ribeirão Preto), escolhido pela própria característica da assistência oferecida, isto é, a pessoa portadora de transtorno mental freqüenta o serviço participando das atividades realizadas no local e retorna para o convívio com a família, não perdendo o contato com seu núcleo familiar. Os sujeitos deste estudo são familiares dos usuários do NAPS que freqüentam atividades do grupo de família, realizadas às sextas-feiras pela manhã e coordenadas por profissionais do serviço. A participação no estudo foi voluntária, mediante leitura e assinatura do termo de consentimento livre e esclarecido. Para a inserção como sujeito, os familiares deveriam estar convivendo com a pessoa portadora de transtornos mentais e apresentarem condições de responderem à entrevista, trazendo assim suas experiências.

Esta pesquisa se insere nos pressupostos dos métodos qualitativos de investigação. No início da coleta de dados não foi estabelecido o número de sujeitos, uma vez que dependíamos da disponibilidade dos familiares para participarem da pesquisa. Detivemonos em oito entrevistas, por julgarmos serem suficientes para o objetivo proposto, de se identificar dificuldades sentidas pelos familiares em seu convívio com o doente mental. Sete foram feitas com mães e uma com a filha de pessoas acometidas por transtorno mental. Por meio dos sujeitos ouvidos neste estudo pudemos verificar que a figura feminina está muito presente no cuidado e no seguimento do tratamento. 
As técnicas de coleta de dados utilizadas foram Observação e Entrevista SemiEstruturada, sendo que no decorrer desta foi utilizada a Técnica Projetiva, mais precisamente o Desenho-Estória com Tema ${ }^{(10)}$. As entrevistas foram realizadas individualmente, nas dependências do serviço de saúde, sendo direcionadas por um roteiro. Após a autorização de cada sujeito utilizou-se o gravador para registro dos relatos. No decorrer das entrevistas recorreu-se ao Procedimento Apresen-tativo Expressivo(11), uma "técnica encoberta de pesquisa" que possibilita a expressão de conteúdos subjacentes. Solicitamos a cada sujeito um desenho de uma família convivendo com a pessoa que está com um problema mental, e depois pedimos um nome para o desenho feito. Este procedimento apresentativo-expressivo, o Desenho-Estória com Tema, permite uma expressão gráfica, a qual, juntamente com a elaboração de uma estória a respeito do desenho, por parte do entrevistado, cria condições de caminhar no sentido da percepção de aspectos inconscientes.

Após a transcrição das entrevistas, realizamos leituras do material utilizando como recurso a Atenção Flutuante ${ }^{(12)}$. Em seguida recorremos à Análise Temática, que pertence à primeira fase da Análise de Enunciação ${ }^{(13)}$. Sendo a Análise Temática transversal, enfoca o conjunto das entrevistas através de uma rede de categorias projetadas sobre os conteúdos. $\mathrm{Na}$ etapa final, recortamos das entrevistas os segmentos correspondentes aos temas emergentes e unidades de significação respectivos a cada categoria.

\section{DISCUSSÃO DOS RESULTADOS}

Os resultados possibilitaram identificar as dificuldades sentidas pela família no convívio com a experiência de transtorno mental. Existe um pensamento central em todas as narrativas: a idéia que o transtorno mental é penoso para quem vivencia a doença, e não menos difícil para a família que convive no cotidiano com esta situação. Destacam-se as seguintes categorias:

\section{Descompasso Temporal}

O descompasso entre o ritmo de vida do paciente e o da família/sociedade aparece nos relatos acompanhado de desânimo, de desesperança frente às possibilidades de reabilitação. Como se houvesse certa impotência di- ante do mundo externo que pede ação, movimento: "ele não tem iniciativa, não tem ilusão, não tem nada!"; "deixa tudo do mesmo jeito, é assim parado para a vida, sabe?"

Estas narrativas sugerem ponteiros de relógios parados no tempo. Essa vivência, em contraste com a continuidade do tempo externo e as solicitações da vida cotidiana, podem gerar conflitos no interior do espaço familiar. A permanência dos sintomas, as falências ou fracassos ligados à vida social do paciente geram frustrações, impotências, angústias, provocando cansaço e isolamento também nos demais membros da família. A rotina no interior do universo familiar tornase repetitiva, nervosa, colocando as pessoas envolvidas em constante contato com sentimentos conflitantes e produtores de tensão. Na produção gráfica na qual foi solicitado o desenho do convívio com o transtorno mental, aparece um traçado com o título "Uma casa". Na estória deste estão contidos isolamento, dificuldades vividas pelos habitantes da casa. Isso remete à reflexão que torna-se difícil o entendimento entre pessoas quando cada uma delas vive tempos diferentes.

A psiquiatria tradicional muitas vezes reforça esta questão quando investiga ou privilegia apenas a orientação do mundo externo. Contrariamente, Silveira ${ }^{(14)}$ enfatiza o mundo interior e destaca a importância de investigações que considerem e explorem o espaço e o tempo interiores. Analisando a história de vida de pessoas acometidas pelo transtorno mental, ela sugere que o tempo subjetivo estagnou a partir de experiências de situações afetivas intensas. A mesma idéia também é enfatizada por Minkowski ${ }^{(15)}$, que destacou o fenômeno da afetividade modificando as vivências de espaço e tempo do doente. Um dos sujeitos, ao elaborar a estória do desenho, sugere esta questão: "as coisas ruins ficaram, e tudo fica guardado na cabeça dele".

A dificuldade de comunicação e de interação gera impotência diante deste descompasso que infringe o convencional, e produz inúmeros desgastes relacionais entre as pessoas envolvidas no interior do núcleo familiar. O desajustamento nos horários habituais é trazido na narrativa:

fica no quarto, dorme de dia, fica no quarto, não dorme de noite, liga a televisão a noite inteira, assim não consegue estudar, não consegue trabalhar.
Transtorno mental: dificuldades enfrentadas pela família 
Maria Alice O. Pereira Alfredo Pereira Jr.
Este descompasso dificulta a participação no jogo social, trazendo também como conseqüência a marginalidade frente ao movimento da vida e um existir apático, sem conciliação com os ciclos naturais: passado, presente e futuro. "Olha eu acho que ela está dormindo porque não está participando da vida". Ao elaborar a estória do desenho este sujeito conta: "é tão feio... é tão triste".

Sendo o fator temporal organizador das vivências pessoais e elemento importante para a apreensão da realidade, pode-se pensar que a dificuldade de comunicação do paciente denota um sofrimento psíquico, ou mesmo uma dificuldade no processo de representação de si mesmo. As narrativas mostram que no interior do convívio da família as diferentes vivências do tempo propiciam desajustes nas relações, desencontros de ritmos para cada elemento do núcleo:

com esse descontrole todo mundo sofre... ele não tem horário, parece que não está ali é parado e vai se isolando.

Este sujeito parece referir à dificuldade de convivência com alguém que vive um tempo sem mudança, sem movimento, sem história. Tal cena estática pode ser estendida para a dinâmica da família; assim, a repetição das cenas faz com que o cotidiano familiar acabe reproduzindo um universo temporal extremamente reduzido, sem passado e sem futuro ${ }^{(16)}$.

\section{Culpa}

O sentimento de culpa em relação ao surgimento da doença foi trazido pelos sujeitos como um fator que os acompanha pela vida, trazendo latente inúmeras interrogações acerca de erros cometidos na criação do/a filho/a, promovendo constante inquérito/conflito interno na tentativa de entendimento do problema:

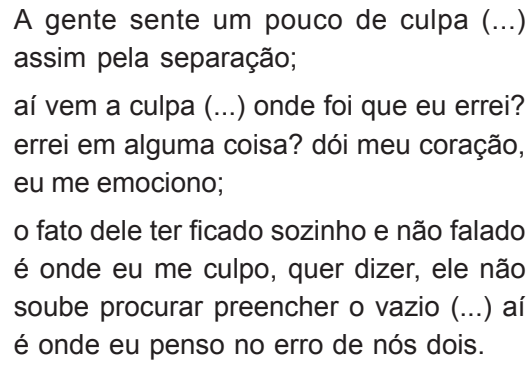

Para estes sujeitos a experiência de doença trouxe o abatimento e o abalo moral do orgulho, da auto-estima da família, como se a pessoa doente fosse o representante das falências do sistema familiar. Assim, a ferida narcísica dos pais fica exposta, estimulando indagações sobre a responsabilidade pela origem e surgimento do quadro psicótico ${ }^{(17)}$. Muitas vezes um jogo de culpas vai se delineando, na busca de possíveis causas para o desencadear da doença. Mecanismos defensivos vão sendo utilizados:

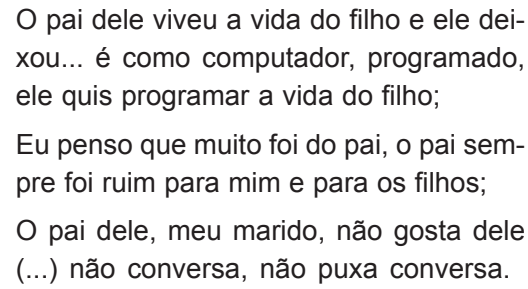

As narrativas, além de denotarem padrões de relações difíceis e complexas, também fazem alusão ao contexto, à dinâmica, à falha de comunicação nas interações familiares, princípio ou base da terapia familiar sistêmica. Os desafetos contidos no interior destes núcleos são dirigidos à figura do pai, aludindo também, o tempo de exposição ou de conflitos no funcionamento da família:

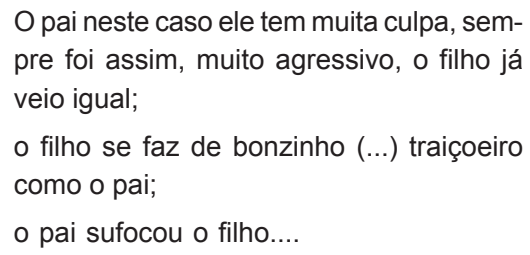

Como título da produção gráfica a qual solicitava o desenho do convívio com a pessoa em transtorno mental, aparece "é um pintinho maltratado", e acima, o desenho de uma pequena ave só, sem pés e sem chão. Quem teria a fragilidade de um pintinho maltratado? O paciente? As pessoas que também convivem com ele? Ou toda as pessoas envolvidas na dinâmica?

A dificuldade em reconhecer a doença frente à apresentação dos sintomas aparece nas falas como mais um fator que culpabiliza, aumentando a sobrecarga sentida:

há muito tempo que eu percebo ele fora do mundo, fora do ar, e ele foi ficando cada vez mais fora do mundo;

Ela já precisava de um tratamento;

Quando ele ficou doente eu não pensei nada, ele manifestou muito diferente;

Não era para pensar que era loucura? Mas não pensava... . 
Mais uma vez o mundo psíquico vai formulando seus mecanismos defensivos; dependendo do modelo de assistência adotado pelos profissionais, pode acentuar a responsabilização e culpa das famílias envolvidas.

No entanto, um sujeito deste estudo, mãe de um paciente ainda jovem portador de uma psicopatologia grave, co-divide seu sentimento de culpa com os profissionais procurados:

Aí eu sempre levei ele no médico. Na consulta ninguém falava o que ele tinha, nem eu. Era na neurologia:— não ele não tem nada; na psiquiatria: — não ele não tem nada.

O mesmo sujeito relata:

O último que eu procurei foi um psiquiatra lá no centro de saúde que falou: ——Ele estuda? Eu disse: estuda; Joga bola? Eu disse: joga; aí ele falou: ah! então ele não tem nada não!

Assim, a dificuldade na identificação do problema também por parte do profissional de saúde, traz a própria representação da doença mental como algo distante, aumentando o nível de angústia vivido pela família.

\section{Desavenças/Conflitos na Família}

As desarmonias vividas pelas pessoas no cotidiano familiar são mencionadas como fator de sobrecarga emocional. Um dos desenhos produzidos pelos entrevistados tem título de "complicado", e a estória deste desenho diz:

é complicado porque a gente sente uma coisa e ele sente outra muito diferente a gente fala uma coisa assim e ele fala outra muito diferente, é complicado, tudo é complicado. Dá muita confusão nesta casa. Viver assim é muito complicado.

Nas narrativas o acúmulo de tensões entre as pessoas da família é citado:

dos irmãos quase todos ficam revoltados, brigam, não aceitam;

o problema é a briga de irmãos (...) a irmã dele não aceita (...) grita, dá uns tapas nele;

A minha outra filha também é meio descontrolada, de vez em quando ela me agride, me ofende, mas tudo de boca.
As hostilidades, os comentários críticos, o intenso envolvimento pessoal podem ser fatores preditivos de recaídas, de reagudização dos sintomas. Uma redução na intensidade de expressão destes fatores pode possibilitar uma maior estabilidade emocional, contribuindo para a diminuição dos conflitos que circulam no interior da vida familiar.

O pouco conhecimento sobre a doença mental é trazido pelos sujeitos, como elemento de desavença e de aumento de sobrecarga:

\begin{abstract}
E muita gente não acredita! (...) Nem quem eu tenho bem próximo que é minha irmã, não acredita! Não acredita na doença, acha que ela finge, acha que ela quer que fique paparicando. Isso maltrata mais ainda e eu não concordo.
\end{abstract}

Este mesmo sujeito estende a falta de compreensão ao atendimento médico recebido e acredita que as trocas promovidas nos grupos de familiares podem contribuir para a melhoria no entendimento dos sintomas apresentados pelo doente:

Então eu acho que é falta de compreensão de tudo, né? (...) mas também dos médicos que querem internar, da falta de compreensão da família. Por exemplo, aqui tem reunião né? Só que os que tem que vir não vêm, não entendem a doença, não participam e isso que é duro. Porque a pessoa está doente e a gente sofre junto né?;

Ela gosta de fazer as coisas que faz aqui, pulseirinha, caixinha, chega em casa, mostra e a minha irmã que não acredita fala que é ridículo, que é bobagem, ela não ajuda, critica....

Na elaboração da estória do desenho conta:

por não conseguirem que os outros compreendam fica difícil, uma pessoa que não tem vontade de viver, de ficar aqui. A tristeza vem da falta de compreensão....

Estes relatos evidenciam o pensamento que a informação sobre a natureza dos sintomas e sobre o tratamento podem melhorar a compreensão e a estabilidade emocional no contexto da família. Há grande valor nos grupos multifamiliares, onde as trocas podem acontecer por meio do encontro com "os outros", da expressão de emoções e sentimentos esperados nesses grupos, além do aprendizado de informações que poderão trazer mudanças de atitude para com a doença men-
Transtorno mental: dificuldades enfrentadas pela família 
Maria Alice O. Pereira Alfredo Pereira Jr. tal e, conseqüentemente para a pessoa que sofre essa experiência ${ }^{(6)}$. Os sujeitos ouvidos reconhecem a importância dos grupos desenvolvidos no serviço de saúde. Por outro lado, referem com veemência a questão da sobrecarga maior voltada para a figura materna e esta aparece assumindo o legado a ela atribuído.

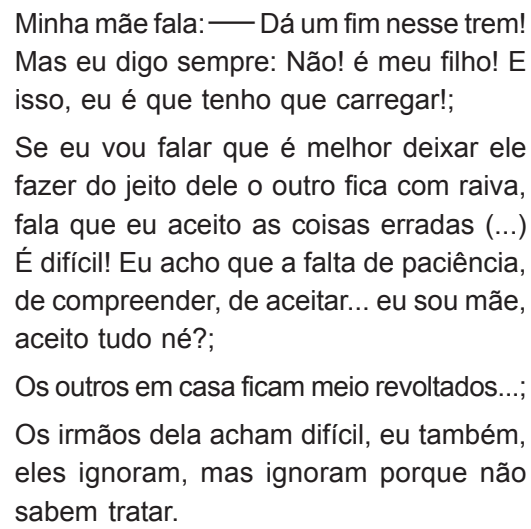

Se eu vou falar que é melhor deixar ele fazer do jeito dele o outro fica com raiva, fala que eu aceito as coisas erradas (...) É difícil! Eu acho que a falta de paciência, de compreender, de aceitar... eu sou mãe, aceito tudo né?;

Os outros em casa ficam meio revoltados...;

Os irmãos dela acham difícil, eu também, eles ignoram, mas ignoram porque não sabem tratar

Vê-se que há necessidade da família em encontrar um local no cérebro na tentativa de entendimento do "processo incompreensível da doença que não apresenta dor física como sintoma principal'"(18). A experiência do sofrimento psíquico é a da intermitência entre o sofrimento e o não sofrimento, havendo assim períodos de diminuição dos sintomas ${ }^{(19)}$. Porém, as narrativas mostram que oscilações referentes aos sintomas e as condutas apresentadas pela pessoa com transtorno mental podem confundir os integrantes do núcleo familiar causando conflitos:

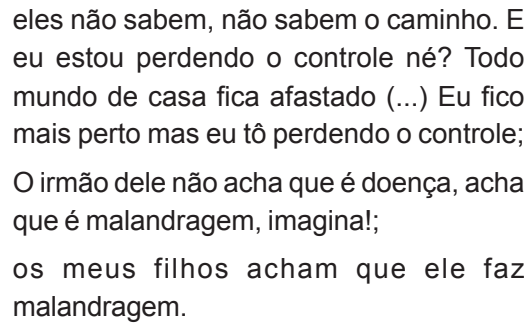

Assim, estes sujeitos evidenciam a vulnerável estabilidade emocional do contexto familiar que diminui a capacidade individual de interação com o paciente e aumenta a tensão deste contexto.

\section{Perdas}

Todas as pessoas ouvidas neste estudo estão convivendo com as questões advindas da doença mental há mais de quatro anos, e, portanto, vêm passando por processos readaptativos neste período. Os relatos trazem vivências de perdas, de lamentos, e com pesar, mencionam o que o paciente foi no passado: ela era uma pessoa boa assim de conversar, trabalhava, sempre muito ativa, adorava se arrumar, de repente não queria se arrumar, não queria mais nada...;

é fogo porque você lembra dela boa, dela trabalhando....

Há um processo de conhecimento que os familiares demonstram ter adquirido por suas vivências, apresentando sensibilidade advinda das experiências de sofrer psíquico e de lidarem com as situações ${ }^{(20)}$. Assim, os sujeitos demonstram que o conhecimento adquirido vem a custa de experiências difíceis, decorrentes do convívio com a pessoa bastante diferente dos sonhos sonhados:

\section{Ele era um menino inteligente, a professo- ra elogiava (...) ele perdeu a personalida- de dele; \\ E ele que queria tanto estudar, queria fa- zer medicina, dizia que ia continuar estudando; \\ Eu tinha vontade que meu filho conse- guisse trabalhar, casar, ter casinha dele, mas ele não consegue e é triste e eu sinto uma dor assim pelo meu filho.}

$\mathrm{Na}$ estória do desenho, o sujeito deu como título o nome próprio do paciente e conta: "este era um menino bom, que foi bom até os 22 anos...”.

Diante do impacto do adoecimento de um membro da família, os sujeitos demonstram viver um processo compulsório de reorganização de suas dinâmicas. Porém, o sentimento de perda permanece trazendo desgaste emocional, aumentando o sofrer psíquico e reduzindo as possibilidades de trocas afetivas que de fato propiciem interlocuções construtivas e pautadas na realidade. Assim, mais ou menos conscientes, as narrativas trazem a dificuldade em lidar com o real e o desejo de não viver a situação. Na elaboração da estória do desenho aparece: "ela tinha vontade de ver aquele filho, aquela pessoa normal como ela ou outra pessoa qualquer".

As restrições na vida social ou nas rotinas de trabalho são citadas como prejuízos vividos e estes determinam estados emocionais no interior do núcleo familiar:

E aí eu deixei de sair de casa porque é difícil para sair;

Aí eu fui faltando do serviço, chorava muito, eu chorava tanto, vivia com o olho vermelho. O que eu chorei, chorei muito, acho que nem tenho mais lágrimas! Hoje eu xingo, não choro mais, fiquei seca, dura!. 
A partir da convivência com a pessoa com transtorno mental a rotina dos membros da família é alterada, em especial no que tange ao cuidador mais próximo, podendo trazer desesperança quanto à perspectiva de vida, como se não houvesse caminhos além do ser doente mental. Há pelo menos dois sentidos da palavra saúde: de modo absoluto, como conceito normativo que define um tipo ideal de estrutura e de comportamento orgânico; e a saúde adjetivada, como conceito descritivo que define certa disposição e reação de um organismo individual em relação às doenças possiveis ${ }^{(21)}$. Desse modo, dependendo do modelo utilizado pelos profissionais de saúde e pela família, o modo de lidar com as questões inerentes ao convívio com a pessoa com transtorno mental contribuem para determinar as dinâmicas familiares.

\section{CONSIDERAÇÕES FINAIS}

Entendemos que a mudança das diretrizes da assistência em saúde mental, optando pelo atendimento em regime aberto, implica em uma importante mudança da relação do profissional de saúde mental com as famílias dos pacientes, importantes parceiras no processo de reabilitação. A falta de orientação às famílias pode fazer com que eclodam conflitos e descompassos entre o paciente e a dinâmica familiar, com prejuízos para o processo terapêutico.

No presente estudo, identificamos quatro categorias relevantes para se entender o relacionamento do paciente com a família. Destas categorias, duas se encontram presentes no modelo anterior, em que o paciente era excluído da vida familiar pelo internamento no hospital psiquiátrico: a per- $d a$ e a culpa. O sentimento de perda muitas vezes advinha da ausência do convívio com o ente, e a culpa, além de incidir sobre possíveis responsabilidades da família no processo que conduzia à doença, também poderia dizer respeito ao próprio ato de internamento.

No contexto da assistência em regime aberto, o paciente é reinserido ou mantido no convívio familiar, levando possivelmente à emergência das duas outras categorias identificadas, o descompasso temporal quanto aos ritmos da vida diária, e a desavenças ou conflitos gerados pelo convívio com o paciente. Através dos relatos obtidos neste estudo pudemos notar que os familiares dos pacientes pedem escuta, acolhimento e ajuda para amenizar sua experiência com a pessoa acometida de transtorno mental.

Entendemos estas dificuldades como desafios para os profissionais da área, pois a partir das práticas renovadas de assistência ampliam-se suas possibilidades de atuação. Para tal, é necessário compreender a demanda que impele à busca de instrumentos que ofereçam o suporte necessário para a família do doente mental. Estar próximo do universo familiar significa estar em contato com realidades complexas e conflitantes, que pedem uma assistência voltada à cooperação e à integração, uma vez que as expectativas dos familiares têm relação direta com as expectativas dos profissionais de saúde. O convívio com o portador de transtorno mental impõe aos seus familiares a vivência de sentimentos e emoções que, consciente ou inconscientemente, são difíceis de elaborar e entender. Isto evidencia a grande necessidade de intervenções que acolham o sofrimento apresentado, considerando a subjetividade das pessoas e favorecendo a dinâmica de ajuda mútua.
Transtorno mental: dificuldades enfrentadas pela família

\section{REFERÊNCIAS}

(1) Amarante P. Loucos pela vida: a trajetória da reforma psiquiátrica no Brasil. Rio de Janeiro: Fiocruz; 1998

(2) Dell'Acqua G. Utenti, famiglie e servizi di salute mentale. In: Dell'Acqua G, organizador. Per la Salute Mentale. $3^{a}$ ed. Trieste: Servizio di salute Mentale; 1992.

(3) Evaristo P. Gestão da psiquiatria na comunidade. UNOPAR Cient Cienc Biol Saúde 2000: 2: $1: 27-34$.
(4) Falloon I, Magiano L, Morosini P. Intervento psicoeducativo integrato in psichiatria. Trento: Erickson, 1997.

(5) Koga M. Convivência com a pessoa esquizofrênica: sobrecarga familiar. [dissertação] Ribeirão Preto: Escola de Enfermagem de Ribeirão Preto/USP; 1997.

(6) Zanus PM. II Lavoro com le Famiglie ad Alto Carico. Trieste: Università Degli Studi di Trieste/Istituto di Clinica Psichiatrica; 1993.

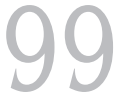

Rev Esc Enferm USP 2003; 37(4):92-100 
Maria Alice O. Pereira Alfredo Pereira Jr.
(7) Waidman MAP, Jouclas VMG, Stefanelli MC. Família e doença mental. Fam Saúde Desenv $1999 ; 1: 1 / 2 ; 27-32$.

(8) Jeon YH, Maidar I. Caring for family members with chronic mental illness. Qual Health Res 1998; 8: 5: 694-706.

(9) Tsu TMJA. A internação psiquiátrica e o drama das famílias. São Paulo: EDUSP, 1993.

(10) Tsu TMJA. Vício e loucura: estudo de representações sociais de escolares sobre a doença mental através do uso de procedimento de desenhos-estórias com tema. Bol Psic 1994/ 95: 41: 47-55.

(11) Vaisberg TMJ. O uso de procedimentos projetivos na pesquisa de representações sociais: projeção e transicionalidade. [tese] São Paulo (SP): Instituto de Psicologia USP; 1995.

(12) Laplanche J, Pontalis JB. Vocabulário de psicanálise. São Paulo: Martins Fontes; 1992.

(13) Bardin L. Análise de conteúdo. Lisboa: Edições 70; 1994.

(14) Silveira N. O mundo das imagens. São Paulo: Ática; 1992.
(15) Minkowski E. Temporalità vissuta e semântica esistenziale. Torino: Edizoni di Filosofia; 1967.

(16) Ruffiot A. O poder absoluto: a imago dos pais combinados ou a anti-cena primária. In: Vilhena J, organizador. Escutando a família: uma abordagem psicanalítica. Rio de Janeiro: Relume-Dumará, 1991. p. 31-43.

(17) Melman J. Repensando o cuidado em relação aos familiares de pacientes com transtorno mental. [dissertação] São Paulo: Faculdade de Medicina da USP; 1998.

(18) Villares C. Representações de doença por familiares de pacientes com diagnóstico de esquizofrenia. [dissertação] São Paulo: Universidade Federal de São Paulo; 1996.

(19) Saraceno B. La Fine dell' Intrattenimento. Milano: Etas Libre; 1995.

(20) Costa JF. Ordem médica e norma familiar. Rio de Janeiro: Graal; 1983.

(21) Canguilhem G. O normal e o patológico. $4^{\mathrm{a}}$ ed. Rio de Janeiro: Forense Universitária; 1995. 